\title{
Fatigue Strength Evaluation of Pressurizer Wall Structure in Pressurized Water Reactor
}

\section{Roziq Himawan}

Center for Nuclear Reactor Technology and Safety - BATAN PUSPIPTEK Area Building No. 80 Serpong, Tangerang Selatan 15310, Indonesia

\section{Abstract}

Fatigue strength evaluations have been performed to the pressurizer component in Pressurized Water Reactor. Fatigue is the main failure mechanism of material during system in operation. Therefore, this evaluation becomes important to be performed since the pressurizer has a very important function in the reactor's system. Analysis was performed by using Nuclear Power Plant operation data from 40 years operation and base on Miner theory. This analysis covered all stress level experienced by the

Corresponding Author: Roziq Himawan; email:

roziqh@batan.go.id

Received: 29 July 2016

Accepted: 21 August 2016

Published: 21 September 2016

\section{Publishing services}

provided by Knowledge E

(c) Roziq Himawan. This article is distributed under the terms of the Creative Commons Attribution License, which permits unrestricted use and redistribution provided that the original author and source are credited.

Selection and Peer-review under the responsibility of the ICONETS Conference Committee.

\section{G OPEN ACCESS} reactor during the service. To determine the value of fatigue usage factor $\alpha$ flatigue curve of SA 533 material was applied. Analysis results show that the cumulative fatigue damage during 40 years in operation is $4,23 \times 10^{-4}$. This value still far enough below failure criteria, which a value is 1 . Therefore, the pressurizer design has already fulfilled the design qualification in term of fatigue aspect.

Keywords: pressurizer, fatigue usage factor, cumulative fatigue damage

\section{Introduction}

Primary cooling system of Pressurized Water Reactor (PWR) has a high operating pressure of about $15 \mathrm{MPa}$ [1]. So that the main components in the nuclear island, that are reactor pressure vessel, pressurizer, steam generators and the primary coolant piping system should be able to retain this operating pressure. Therefore, the integrity of the mechanical structure of these components must be guaranteed for all operation condition including severe accident and transient conditions. It's known that one of the main causes of catastrophic failure of a structure is due to fatigue phenomenon [2]. Fatigue is the phenomenon in which lead into material degradation due to cyclic loading. Fatigue phenomenon may also occur in the main nuclear components during reactor service life due to transient condition such as reactor start-up and shut-down, increasing and decreasing power. These transient conditions will generate cyclic loads to the structures. These loads could be a mechanical load or/and thermal load due to temperature stratification. During normal conditions, reactor components were designed to have long fatigue life. However, the operating conditions and environment could shorten the fatigue life. Extreme environmental conditions could induce corrosion to the material. Corrosion will initiate fatigue crack prematurely $[3,4]$. By these reasons, many studies related to the fatigue and fatigue 
crack propagation characteristics of the reactor components and associated factors have been intensively performed $[5,6]$.

Pressurizer is one of the safety-related reactor components which have a function to maintain the reactor operating pressure. As a result pressurizer endures various types of loads. Therefore the structural integrity of the pressurizer should be determined through conservative stress analysis and should fulfil design requirement and stress limit which corresponds to the design conditions and additional conditions [7].

In this study, the fatigue life analysis was done for pressurizer components by calculation method. The results of the analysis are then compared with the standard design in order to determine the reliability of pressurizer.

\section{Theory}

Fatigue strength (it's also called as fatigue limit or endurance limit) of material is determined by performing fatigue testing using several number of specimens and varying alternating stress amplitude $\left(\sigma_{a}\right)$ and mean stress $\left(\sigma_{m}\right)$. The tests are performed until the specimen fracture with the cycle number of $N_{c}$ or exceeds $N_{L}$ [8]. Testing results then, are plotted on the graph represent the relationship between stress $(\sigma)[D Q G]$ cycle number $(N)$. This diagram is well known, as fatigue curve or Wohler diagram. In general, this diagram is drawn in $\log \sigma-\log N$ coordinate as shown in Fig. 1. Fatigue curve in $\log \sigma-\log N$ coordinate is a polygonal line. For exception, the transition part is a curve. The intersection between an oblique line and horizontal line represents theoretical limit of cycle and denoted by $\mathrm{N}_{\mathrm{o}}$. In performing fatigue testing, the type of loading was determined as an actual load type in the operating system. Thus, the load type could be either tensile loads, torsional load, bending load, rotating-bending load, etc. In a detailed Wohler diagram, the diagram area is divided into three parts, namely the low-cycle fatigue strength (LCF), highcycle fatigue strength (HCF), and sub-fatigue limit (SF) as shown in Fig. 2.
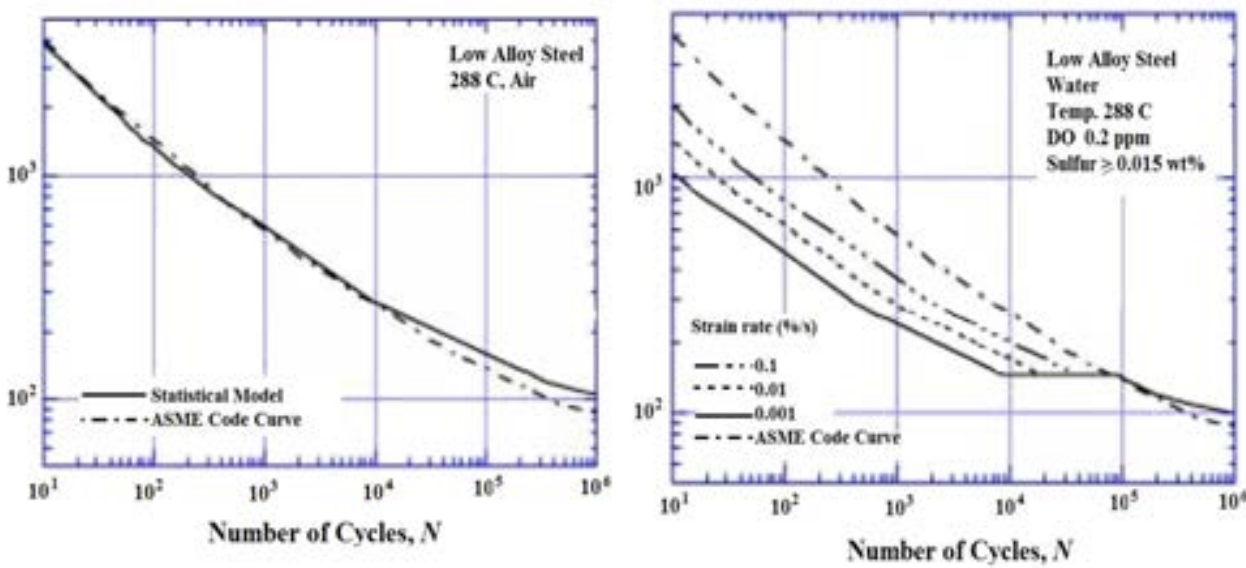

Figure 1. Fatigue diagram for Ferritic steel SA 533 B [9]. 


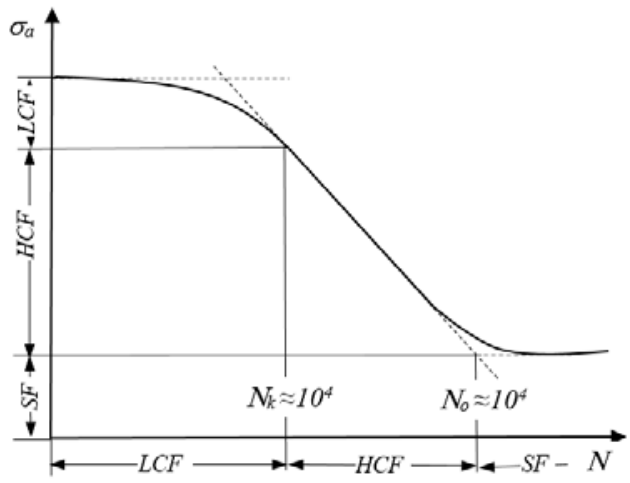

Figure 2. Wohler Diagram which include zone of low-cycle fatigue strength (LCF), high-cycle fatigue strength (HCF), and sub-fatigue limit (SF) [8]

Design of reactor components should conform to a specific standard applied in vendor countries such as ASME standards which is applicable in the United States [7]. The standard sets all the parameters or mechanical behavior of the material used in the reactor, including fatigue aspect. The ASME standard section III Division 1, Sub Division NB was applied to the design of nuclear reactor components. Therefore, in this study, the fatigue strength analysis were performed according to this standard.

Fatigue strength analysis is performed using the peak stress which is a resultant of various loads in each level of operation. Then, amplitude stress $\left(S_{a}\right)$ were calculated using peak stress according to equation (1) [9].

$$
S_{a}=\frac{S_{p}}{2}
$$

The value of stress amplitude $\left(S_{a}\right)$ is put in the S-N curve shown in Appendix I of ASME section III (see Figure 1) in order to determine the fatigue life of components. However, the fatigue life determined here is the life represents for one loading level, only. In fact, in the real operation, each reactor component may experience various loading levels and various cyclic numbers. To determine the accumulative fatigue life due to various loading levels, fatigue usage factor method was applied. Fatigue Usage Factor was calculated by Miner method and according to equation (2) and (3). Firstly, each ratio between loading cycles during reactor operation with the number of cycles at Wohler diagram for a certain loading level was calculated using equation (2). After all loading levels were calculated, then cumulative fatigue damage was calculated using equation (3). From this calculation, the value of the cumulative fatigue usage factor in a structure should not exceed 1 . The value of 1 , it means the components will experience failure due to fatigue phenomenon. Therefore, value 1 represents failure criteria.

$$
\begin{aligned}
& \alpha=\frac{n_{i}}{N_{i}} \\
& C F D=\sum \frac{n_{i}}{N_{i}} \leq 1
\end{aligned}
$$


with $\alpha$ is cumulative fatigue usage factor, $\mathrm{n}$ is cycle number during reactor operation for one loading level, $\mathrm{N}$ is cycle number in Wohler diagram for associated loading level, and CFD is cumulative fatigue damage.

\section{Methodology}

As described in the previous section, in this study, the fatigue strength analysis were performed to the pressurizer with a design as shown in Fig. 3. Ferritic steel of type SA 533 B was used for pressurizer material as those used in reactor pressure vessel. Design parameter of pressurizer was shown in Table 1, whilst mechanical properties and thermal properties of material were shown in Table 2.

\begin{tabular}{|c|c|c|}
\hline No & Parameter & Value \\
\hline 1 & Pressure design, $\mathrm{MPa}$ & 17.58 \\
\hline 2 & Temperature design, ${ }^{\circ} \mathrm{C}$ & 371 \\
\hline 3 & Normal operation pressure, MPa & 15.82 \\
\hline 4 & Normal operation temperature, ${ }^{\circ} \mathrm{C}$ & 344 \\
\hline 5 & Vessel volume, $\mathrm{m}^{3}$ & 68 \\
\hline 6 & Water volume under normal operation, $\mathrm{m}^{3}$ & 31.4 \\
\hline 7 & Steam volume under normal operation (full capacity), $\mathrm{m}^{3}$ & 36.5 \\
\hline 8 & Installed heater capacity, kW & 2,400 \\
\hline
\end{tabular}

TABLE 1. Design parameter of pressurizer

\begin{tabular}{|c|l|c|}
\hline No & \multicolumn{1}{|c|}{ Sifat Material } & Nilai \\
\hline 1 & Young Modulus E (GPa) & 191 \\
\hline 2 & Poisson Ratio; $\mathrm{U}$ & 0.3 \\
\hline 3 & $\mathrm{k}\left(\mathrm{W} / \mathrm{m}^{\circ} \mathrm{C}\right)$ & 40.9 \\
\hline 4 & $\rho(\mathrm{kg} / \mathrm{m} 3)$ & 7784 \\
\hline 5 & $\alpha\left(\mathrm{m} / \mathrm{m}^{\circ} \mathrm{C}\right)$ & $12.5 \mathrm{e}^{-6}$ \\
\hline 6 & Yield Stress ; $\mathrm{MPa}$ & 345 \\
\hline 7 & Ultimate tensile strength, $\mathrm{MPa}$ & $550-690$ \\
\hline
\end{tabular}

TABLE 2. Mechanical and thermal properties of SA 533 B material

In the analysis of fatigue strength, the stress values which occur during reactor operation (for a specific load level) and cycle number were needed. In the operation of nuclear power reactors, the operating level is divided into five levels, namely the operating conditions level A, level B, level C, level D and testing conditions [7]. For each level there are a several stress value with a certain cycle number. In this analysis of the fatigue strength, the stress value and the frequency of occurrence data are as a result from the operation of the reactor for 40 years. These data are shown in Table 3 [11].

Operation conditions Level $\mathrm{C}$ and Level $\mathrm{D}$ are not taken into account because of the frequency of occurrences are very rare. Emergency Conditions and infrequent Incidents are categorized into operating conditions Level C while faulted and Limiting Conditions Faults are categorized into operating conditions Level D. Likewise, the test 
conditions are not considered in this analysis because small number of occurrences during reactor's service life.

\begin{tabular}{|c|l|r|}
\hline \multicolumn{3}{|c|}{ MOZZLE SCHEDULE } \\
\hline NO. & SERVICE & $\begin{array}{c}\text { NO. } \\
\text { REQO }\end{array}$ \\
\hline 1 & MUMWAY & 1 \\
2 & SUROE & 1 \\
3 & SPRAY & 1 \\
4 & POSAV & 4 \\
5 & INSTRUMENT TAPS & 7 \\
6 & INSTRUMENT TAPS & 2 \\
7 & TEMPERTTURE & 1 \\
8 & HEATER & 48 \\
\hline
\end{tabular}

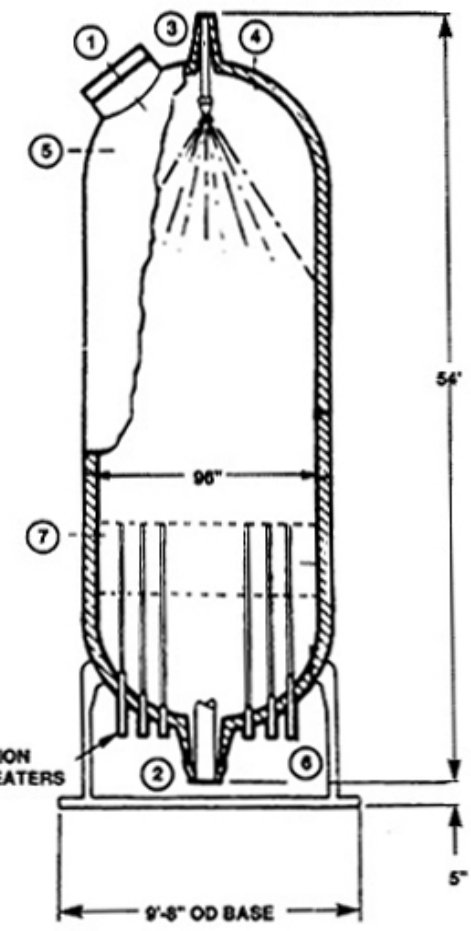

Figure 3. Schematic design of pressurizer vessel

\begin{tabular}{|c|c|c|c|c|c|}
\hline \multicolumn{2}{|c|}{ Load No } & \multirow[t]{2}{*}{ Transient Design } & \multicolumn{2}{|c|}{ Stress value (MPa) } & \multirow{2}{*}{$\begin{array}{c}\text { Cycles during } \\
40 \text { years }\end{array}$} \\
\hline & & & Max. & Min. & \\
\hline \multirow{9}{*}{ 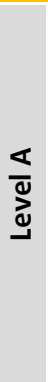 } & $1 / 2$ & Heat-ap/cooldown & 160,9 & 0,0 & 200 \\
\hline & 3 & Unit loading/unloading & 159,2 & 160,6 & 500 \\
\hline & $4 / 5$ & Plant loading/unloading & 160,7 & 158,0 & 13.200 \\
\hline & $6 / 7$ & Step load change of $10 \%$ & 164,4 & 157,6 & 2.000 \\
\hline & 8 & Steam dump & 167,5 & 150,5 & 200 \\
\hline & $9 a$ & Steady state fluctuation (A) & 160,9 & 158,8 & $1,5 \times 105$ \\
\hline & $9 b$ & Steady state fluctuation (B) & 161,3 & 160,5 & $3 \times 106$ \\
\hline & 10 & Feedwater cycling & 154,9 & 162,9 & 2.000 \\
\hline & $11 / 12$ & Loop out service & 167,6 & 160,4 & 80 \\
\hline \multirow{10}{*}{$\frac{\infty}{\Phi}$} & 15 & Loss of load & 187,7 & 131,7 & 80 \\
\hline & 16 & Loss of Power & 176,0 & 132,1 & 40 \\
\hline & 17 & Partial loss of flow & 164,7 & 138,2 & 80 \\
\hline & $18 a$ & Reactor trip A & 160,9 & 142,7 & 230 \\
\hline & $18 b$ & Reactor trip B & 160,9 & 114,5 & 160 \\
\hline & $18 c$ & Reactor trip C & 160,9 & 114,5 & 10 \\
\hline & 19 & Inadvertent depressurization & 160,9 & 9,3 & 20 \\
\hline & 20 & Inadvertent startup & 167,5 & 142,1 & 10 \\
\hline & 21 & Control rod drop & 160,9 & 131,0 & 80 \\
\hline & 22 & Inadvertent safety injection & 164,0 & 143,7 & 60 \\
\hline
\end{tabular}

TABLE 3. Load condition : Level A and Level B [7] 


\section{Result and Discussion}

Table 4 shows CFD analysis results below. In this table, column which indicates transient conditions are removed and denoted by number which has correlation with Table 3. $\Delta \sigma$ shows the stress amplitude representing a stress difference between the maximum and minimum stress. The notation which represents number of cycles for 40 years was changed became $n_{i} . N_{i}$ column states the fatigue life at a certain stress level, which is determined by $\mathrm{S}-\mathrm{N}$ curve as shown in Figure 1. In this analysis, S-N curve of SA 533 B under water and temperature $288^{\circ} \mathrm{C}$ was used. In this figure, S-N graph of ASME standard and various result from different strain rate were plotted. Furthermore, cumulative fatigue damage, $\alpha$, was calculated using equation (2).

\begin{tabular}{|c|c|c|c|c|c|c|c|}
\hline \multicolumn{2}{|c|}{ Load No. } & \multicolumn{2}{|c|}{ Nilai tegangan (MPa) } & \multirow[b]{2}{*}{ (MPa) } & \multirow[t]{2}{*}{$\mathbf{n}_{\mathrm{i}}$} & \multirow[t]{2}{*}{$\mathrm{N}_{\mathrm{i}}$} & \multirow[t]{2}{*}{$\alpha$} \\
\hline & & Maks. & Min. & & & & \\
\hline \multirow{9}{*}{ 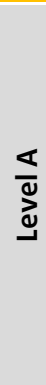 } & $1 / 2$ & 160,9 & 0,0 & 160,9 & 200 & $4,8 \times 10^{4}$ & $4,17 \times 10^{-3}$ \\
\hline & 3 & 159,2 & 160,6 & 1,4 & 500 & $1,0 \times 10^{10}$ & $1,0 \times 10^{-8}$ \\
\hline & $4 / 5$ & 160,7 & 158,0 & 2,7 & 13.200 & $1,0 \times 10^{10}$ & $1,32 \times 10^{-9}$ \\
\hline & $6 / 7$ & 164,4 & 157,6 & 6,8 & 2.000 & $1,0 \times 10^{10}$ & $2,0 \times 10^{-10}$ \\
\hline & 8 & 167,5 & 150,5 & 17 & 200 & $1,0 \times 10^{10}$ & $2,0 \times 10^{-8}$ \\
\hline & $9 a$ & 160,9 & 158,8 & 2,1 & $1,5^{\times} \times 10^{5}$ & $1,0 \times 10^{10}$ & $1,5 \times 10^{-5}$ \\
\hline & $9 b$ & 161,3 & 160,5 & 0,8 & $3,0 \times 10^{6}$ & $1,0 \times 10^{10}$ & $3,0 \times 10^{-4}$ \\
\hline & 10 & 154,9 & 162,9 & 8 & 2.000 & $1,0 \times 10^{10}$ & $2,0 \times 10^{-10}$ \\
\hline & $11 / 12$ & 167,6 & 160,4 & 7,2 & 80 & $1,0 \times 10^{10}$ & $8,0 \times 10^{-9}$ \\
\hline \multirow{11}{*}{$\frac{\infty}{\stackrel{\varpi}{d}}$} & 15 & 187,7 & 131,7 & 56 & 80 & $1,0 \times 10^{10}$ & $8,0 \times 10^{-9}$ \\
\hline & 16 & 176,0 & 132,1 & 43,9 & 40 & $1,0 \times 10^{10}$ & $4,0 \times 10^{-9}$ \\
\hline & 17 & 164,7 & 138,2 & 26,5 & 80 & $1,0 \times 10^{10}$ & $8,0 \times 10^{-9}$ \\
\hline & $18 a$ & 160,9 & 142,7 & 18,2 & 230 & $1,0 \times 10^{10}$ & $2,3 \times 10^{-8}$ \\
\hline & $18 b$ & 160,9 & 114,5 & 46,4 & 160 & $1,0 \times 10^{10}$ & $1,6 \times 10^{-8}$ \\
\hline & $18 \mathrm{C}$ & 160,9 & 114,5 & 46,4 & 10 & $1,0 \times 10^{10}$ & $1,0 \times 10^{-9}$ \\
\hline & 19 & 160,9 & 9,3 & 151,6 & 20 & $5,5^{\times} \times 10^{4}$ & $3,6 \times 10^{-4}$ \\
\hline & 20 & 167,5 & 142,1 & 25,4 & 10 & $1,0 \times 10^{10}$ & $1,0 \times 10^{-9}$ \\
\hline & 21 & 160,9 & 131,0 & 29,9 & 80 & $1,0 \times 10^{10}$ & $8,0 \times 10^{-9}$ \\
\hline & 22 & 164,0 & 143,7 & 20,3 & 60 & $1,0 \times 10^{10}$ & $6,0 \times 10^{-9}$ \\
\hline & & & & & & $\mathrm{CFD}=$ & $4,85^{\times} \times 10^{-3}$ \\
\hline
\end{tabular}

TABLE 4. Calculation result of Cumulative Fatigue Damage

As shown in Figure 1, curve $C$ has endurance or fatigue limit at stress value of about $90 \mathrm{MPa}$. Thus, stress values below $90 \mathrm{MPa}$ will not result damage in material due to fatigue phenomenon. However, to quantify the value of $\alpha$ at all stress levels in Table 4 , for stress values below $90 \mathrm{MPa}$, we assume to have $N_{i}$ of $1.0 \times 10^{10}$. After all of $\alpha$ value were calculated, then summed to obtain the CFD.

The calculation of cumulative fatigue damage from ASME Standard Curve gave a result to a value of $4.85 \times 10^{-3}$. This value is extremely small compared to the value of 1 , where a value of 1 indicates that the components will fail due to fatigue phenomena. As shown in Table 4, that the value of CFD $=4.85 \times 10^{-3}$ is accumulated during 40 years of reactor operation. Thus, it can be assumed, with the same mode of operation, the reactor is still safe from the phenomenon of fatigue even it's operated for 80 years. However, in real operation experience, a lot of reports of leaks in nuclear reactor safety component triggered by corrosion phenomena. Which resulted 
in the occurrence of corrosion or pitting of the notch on the surface of the material, can spread into larger cracks due to repeated load.

\begin{tabular}{|c|c|c|}
\hline No. & S-N Curve condition & CFD \\
\hline 1. & ASME Standard Curve & $4.85 \times 10^{-3}$ \\
\hline 2. & $0.1[\% / s]$ strain rate & $1.05 \times 10^{-2}$ \\
\hline 3. & $0.01[\% / s]$ strain rate & $2.16 \times 10^{-2}$ \\
\hline 4. & $0.001[\% / s]$ strain rate & $4.50 \times 10^{-2}$ \\
\hline
\end{tabular}

TABLE 5. Calculation result of CFD using S-N Curve with various strain rate

Table 5 shows CFD calculation results from ASME standard curve and various condition with different strain rate. CFD from ASME standard curve has the smallest value, whilst the smallest strain rate has the biggest CFD value. From this table, it is known that CFD depends on the strain rate. Even for the biggest CFD value, it is still smaller than 1.

From the results of this analysis can be seen that the design of the pressurizer has fulfilled the requirements of fatigue strength aspect.

\section{Conclusion}

Fatigue strength analysis of pressurizer design were performed. Analysis were performed using nuclear power plant operating data to define various types of stress levels that occur in the pressurizer and cycle / frequency of the stress. Data refer to the operating history for 40 years. From the results of analysis, depends on ASME standard curve and various strain rate, show that the value of cumulative fatigue damage varies from $4.85 \times 10^{-3}$ to $4.50 \times 10^{-2}$. The upper value is still smaller than 1 . It can be concluded that the design meets the standards pressurizer analyzed from the aspect of fatigue strength.

\section{References}

[1] R. Zarghami, et. al., "The Dynamic Modelling of the Pressurizer Surge Tank Transients in Light Water Reactor Nuclear Power Plants", Iranian J. of Science \& Technology, Transaction B, Engineering, Vol. 29, 483-491, 2005

[2] S. Suresh, "Fatigue of Materials", Cambridge University Press, 1998.

[3] Chin-Cheng Huang and Ru-Feng Liu, "Structural integrity analyses for preemptive weld overlay on the dissimilar metal weld of a pressurizer nozzle", International Journal of Pressure Vessels and Piping, Vol. 90-91, 77-83, 2012.

[4] W. A. Van Der Sluys and R. H. Emanuelson, "Fatigue Crack Growth In Reactor Pressure Vessel Materials And Light Water Reactor Environments", Nuclear Engineering and Design, Vol. 119, 379-388, 1990.

[5] J. Y. Huang, et. al., "Fatigue crack growth behavior of reactor pressure vessel steels in air and high-temperature water environments", International Journal of Pressure Vessels and Piping, Vol. 85, 772-781, 2008. 
[6] C. Ensel, et. al., "Stress analysis of a $900 \mathrm{MW}$ pressurizer surge line including stratification effects", Nuclear Engineering and Design, Vol. 153, 197-203, 1995.

[7] "Rules for Construction of Nuclear Power Plant Components", ASME Boiler and Pressure Vessel Code, Section III, 2004.

[8] S. Kocanda, "Fatigue Failure of Metals", Sijthoff \& Noordhoff International Publishers, 1995.

[9] Effects of LWR Coolant Environments on Fatigue Design Curves of Carbon and Low-Alloy Steels, NUREG/CR-6583.

[10] Roziq Himawan, "Respon Panas Transien Dinding Bejana Pressurizer Pada Saat Proses Penyemprotan", Prosiding Seminar Nasional Teknologi Energi Nuklir 2014, Juni 2014.

[11] G. Yagawa and S. Yoshimura, "A study on probabilistic fracture mechanics for nuclear pressure vessels and piping", Int. J. of Pressure Vessel \& Piping, Vol. 13, 97-107, 1997.

[12] Dixon A. G., et al., "Systematic Mesh Development for 3D CFD Simulation of Fixed Beds: Single Sphere Study", Journal of Computer and Chemical Engineering, Vol.35, Issue 7, pp.1171-1185 (2011).

[13] Dehbi A. and Martin S., "CFD Simulation of Particle Deposition on An Array of Spheres Using an Euler/Lagrange Approach", Journal of Nuclear Engineering and Design, Vol.241, Pp.3121-3129 (2011).

[14] Kuijper J. C. et al., "HTTR-N Reactor Physics and Fuel Cycle Studies", Proceeding of 2nd International Topical Meeting on High Temperature Reactor Technology, September 22-24, Beijing (2004).

[15] IAEA-TECDOC-1382, "Evaluation of High Temperature Gas Cooled Reactor Performace: Benchmark Analysis Related to Initial Testing of The HTTR and HTR-10", IAEA, November, Vienna (2003). 